\title{
Profile of Patients Treated in Outpatient Vestibular Rehabilitation at a Hospital in São Paulo
}

\section{Bárbara Vieira Corón, Miguel Angelo Hyppolito², Camila Giacomo Carneiro Barros², Ana Paula do Rego André ${ }^{3}$}

\author{
${ }^{1}$ Faculty of Medicine of Ribeirão Preto, University of São Paulo, Ribeirão Preto, Brazil \\ ${ }^{2}$ Department of Ophthalmology, Otorhinolaryngology and Head and Neck Surgery, Faculty of Medicine of Ribeirão Preto, \\ University of São Paulo, Ribeirão Preto, Brazil \\ ${ }^{3}$ Hospital of Clinical of Ribeirão Preto, Faculty of Medicine of Ribeirão Preto, University of São Paulo, \\ Ribeirão Preto, Brazil \\ Email: ba.vcoro@gmail.com, mahyppo@fmrp.usp.br, camigcbarros@uol.com.br, anadiego@ig.com.br
}

How to cite this paper: Coró, B.V., Hyppolito, M.A., Barros, C.G.C. and do Rego André, A.P. (2019) Profile of Patients Treated in Outpatient Vestibular Rehabilitation at a Hospital in São Paulo. International Journal of Clinical Medicine, 10, 9-15. https://doi.org/10.4236/ijcm.2019.101002

Received: March 12, 2016

Accepted: January 5, 2019

Published: January 8, 2019

Copyright $\odot 2019$ by author(s) and Scientific Research Publishing Inc. This work is licensed under the Creative Commons Attribution International License (CC BY 4.0).

http://creativecommons.org/licenses/by/4.0/

\begin{abstract}
Introduction: Currently it is very common that the search for diagnosis and treatment for curing diseases can cause vertigo or dizziness. Objective: This study sought to characterize the profile of patients seen in the clinic for vestibular rehabilitation in a tertiary hospital in the last 10 years. Methods: Survey questionnaires of patients with dizziness. Results: The prevalence of treated subjects was female $65.3 \%(\mathrm{~N}=439)$. The average age was 54.9 years old. Dizziness type roundabout was more prevalent $33.04 \%(\mathrm{~N}=222)$. Tinnitus occurred in $58.33 \%$ of the population. The time of most observed dizziness was less than 5 years $70.68 \%(\mathrm{~N}=475)$. Neurovegetative symptoms appeared in $63.98 \%(\mathrm{~N}=430)$ of the population. The bilateral normal hearing was more standard $35.26 \%(\mathrm{~N}=237)$. The topographic diagnosis of peripheral origin was the most usual $65.47 \%(\mathrm{~N}=440)$. Conclusion: The peripheral otoneurologic involvement was more prevalent in this population, affecting more women at an average age of 54.9 years old. The most prevalent symptoms were vertigo, nausea, tachycardia, sweating, vomiting and tinnitus, characterizing the peripheral vestibular impairment. The time of dizziness was less than five years. Audiological standard normal curve was predominant and the symptom of tinnitus was the most reported. The most prevalent comorbidity was Hypertension.
\end{abstract}

\section{Keywords}

Dizziness, Epidemiology, Rehabilitation 


\section{Introduction}

A dysfunction of the body balance is generated by a conflict in the integration of sensory information that helps postural control and that can be translated as dizziness [1] [2].

There are many symptoms associated with vertigo and other types of dizziness that can cause inability to perform of the professional, social and domestic activities triggering a series of psychosocial consequences [3]. Among them we have otoneurological symptoms (headache, hearing loss, ear pain, tinnitus and nausea) and psychological symptoms (depression, anxiety, and fear) [2] [4] [5].

Treatment of patients with vestibular dysfunction is an alarming problem. Vestibular dysfunctions are present in $5 \%$ to $10 \%$ of the world population and are the seventh complaint most commonly found in women and the fourth in men [6]. It is estimated that the prevalence of balance disorders and vertigo events is $5 \%$ to $10 \%$ of physician visits per year. In people over 65 years old dizziness is the first reason for a doctor's appointment [7].

Currently it is very common that the search for diagnosis and treatment for the cure of diseases can cause vertigo or dizziness; therefore, it is necessary that the characterization of this population should improve primary care, health promotion campaigns and specific advices. The purpose of this study was to obtain and describe the profile of the patients treated at the vestibular rehabilitation outpatient clinic in a tertiary-level hospital.

This study had the objective of obtaining and describing the profile of patients treated in vestibular rehabilitation clinic in a tertiary level hospital.

\section{Methodology}

\subsection{Ethical Considerations}

The study was approved by the Institutional Ethics Committee (Protocol No. 7277/2013).

\subsection{Procedures}

Data were collected through questionnaires completed in the initial consultation of the subject, by the responsible audiologist of the vestibular rehabilitation service.

The data collected were age, gender, otoneurological diagnosis, presence of vertigo and/or non-rotating, neurovegetative symptoms, auditory symptoms (tinnitus), hearing standard (result of audiometry), time of onset of dizziness, general health (metabolic disorders, vision problems, back problems, cranial trauma, hypertension, stroke and other) and the presence of vestibular tests.

\subsection{Selection and Size of Sample}

To obtain the profile of patients over 10 years of service in vestibular rehabilitation clinic in a tertiary level hospital were randomly selected questionnaires completed between the years 2002 to 2012. This was a retrospective, observational study. 
Exclusion criteria: questionnaires with incomplete data; questionnaires filled out the described period.

\subsection{Data Analysis}

The descriptivestatistics for the data distribution and the coefficient of variation were performed.

\section{Results}

The sample consisted of 672 questionnaires. The distribution of subjects is by gender, mean age and standard deviation (Table 1).

About the type of dizziness presented, 33.04\% $(\mathrm{N}=222)$ of subjects had vertigo, 31.85\% $(\mathrm{N}=214)$ reported non-rotational dizziness and $35.11 \%(\mathrm{~N}=236)$ of subjects reported having both types associated.

Figure 2 shows the distribution of subjects according to the presence of neurovegetative symptoms (nausea, vomiting, sweating, tachycardia and pallor) associated with dizziness $(\mathrm{N}=672)$.

Figure 3 is the distribution of subjects for the presence of caloric testing in electronystagmography and computerized dynamic posturography.

\section{Discussion}

The distribution of the sample according to gender and average age (Table 1) shows the prevalence of dizziness in females agreeing to the world literature works [8] [9] [10] [11]. Women seek more medical care in relation to men and have factors such as variation of monthly hormonal cycle and the climacteric period which has dizziness as one of the main symptoms [12] [13].

Audiological results (Figure 1) indicate that most of the subjects had normal hearing bilaterally $35.26 \%(\mathrm{~N}=237)$. We believe that the fact that the study population is not old, mean age 54.4 years and present mostly $65.47 \%(\mathrm{~N}=440)$ peripheral topographic diagnosis where the most frequent labyrinth pathology is Benign Paroxysmal Positional Vertigo (BPPV) justified audiological research findings.

However, there was no a standard system of classification in results of audiological tests for degree classification of the hearing loss.

About the type of dizziness, more than half of the subjects $35.11 \%(\mathrm{~N}=236)$ had vertigo and non-rotating dizziness associated.

About the presence of associated neurovegetative symptoms (Figure 2) such

Table 1. Distribution of subjects by gender, mean age and standard deviation.

\begin{tabular}{cccccc}
\hline Gender & $\mathrm{N}$ & $\%$ & Mean Age & Standard Deviation & $\begin{array}{c}\text { Coefficient of } \\
\text { Variation }\end{array}$ \\
\hline Female & 438 & $65.3 \%$ & 54.07 & 16.95 & 31.34 \\
Male & 232 & $34.7 \%$ & 55.28 & 17.20 & 31.11 \\
Total & 672 & $100 \%$ & 54.99 & 17.05 & 31 \\
\hline
\end{tabular}




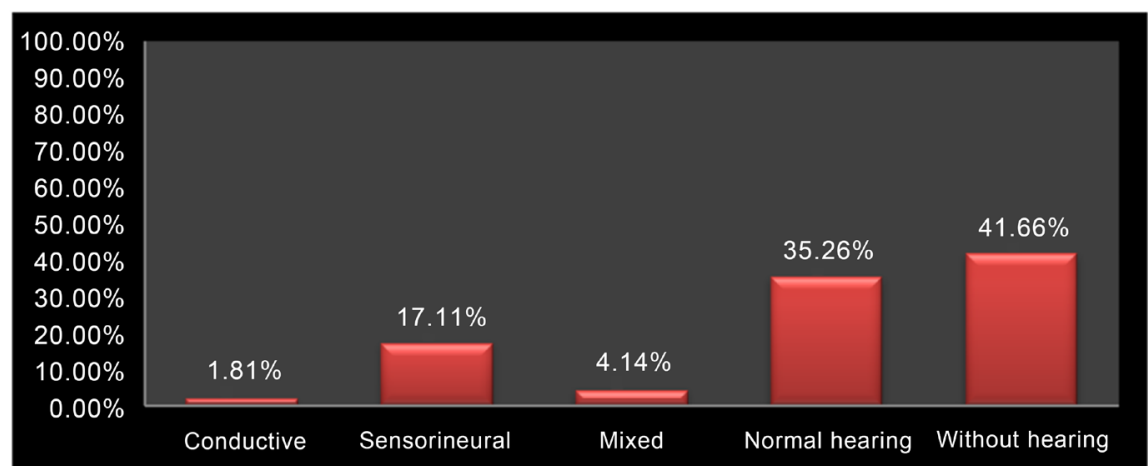

Figure 1. Distribution of subjects according to the type of hearing to the type of hearing loss.

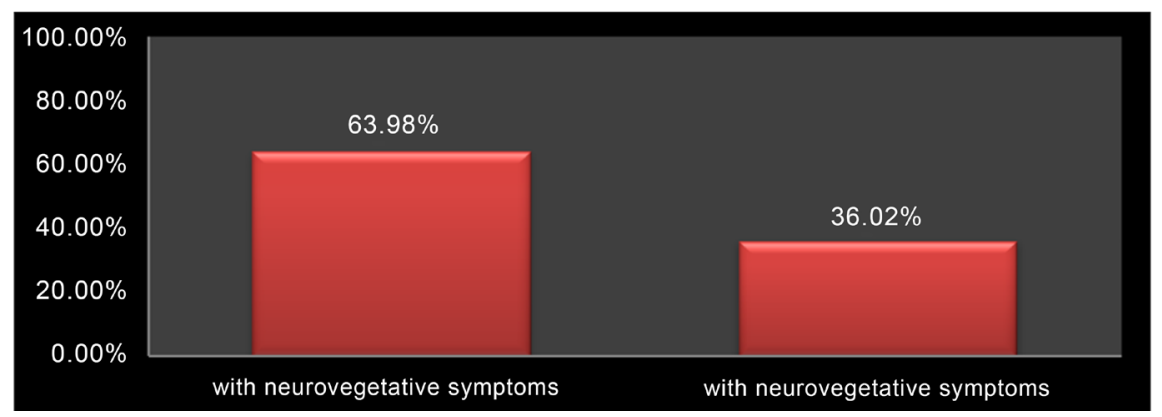

Figure 2. Distribution of subjects according to the complaint of neurovegetative symptoms.

as nausea, sweating, tachycardia and vomiting, most patients $63.68 \%(\mathrm{~N}=428)$ had at least one of the symptoms mentioned in agreement with the study by Cohenetal. Describing these symptoms as frequently reported by patients with dizziness [14].

The tinnitus was hearing manifestation most commonly found in $58.33 \%(\mathrm{~N}=$ 392) of patients, according to the literature [15] [16].

There was a prevalence of $70.68 \%(\mathrm{~N}=475)$ of the subjects of the sample with time corresponding dizziness complaint to a range of 0 to 5 years (Table 2) and this finding similar to that found in the study of Bittar et al. [12].

About the comorbidities found in this study (Table 3), were similar to those found in the works of Nishino et al. [8], Horunbia [17] and Fetter [18] that pointed as comorbidities of the dizziness, cardiovascular deficiency, metabolic disorders, cervical spine disorders, head or neck trauma, stroke, vision impairment, psychological disorders such as panic attacks and anxiety. The main comorbidity found in the study was hypertension $41.51 \%(\mathrm{~N}=279)$ followed by a visual disorder $36.30 \%(\mathrm{~N}=244)$.

About the presence of caloric test of Electronystagmography and Computerized Dynamic Posturography (Figure 3), the percentage of subjects without examination was $45.30 \%(\mathrm{~N}=304)$ of the study population. It is believed that this was given obtained because the majority of the population studied have topographic diagnosis of peripheral origin, and the disease most commonly found is the Benign Paroxysmal Positional Vertigo, where the clinical examination set 
Table 2. Distribution of subjects according to the time of dizziness.

\begin{tabular}{ccc}
\hline Complaint Time & $\mathrm{N}$ & $\%$ \\
\hline 0 - 5 years & 475 & 70.68 \\
6 - 10 years & 100 & 14.89 \\
Over 10 years & 97 & 14.43 \\
Total & 672 & 100 \\
\hline
\end{tabular}

Table 3. Main comorbidities presented by the study population.

\begin{tabular}{ccc}
\hline Comorbidity & $\mathrm{N}$ & $\%$ \\
\hline Systemic arterial hypertension & 279 & 41.51 \\
Visual problems & 244 & 36.30 \\
Metabolic diseases & 184 & 27.38 \\
Migraine & 82 & 12.20 \\
Trauma cranial & 74 & 11.01 \\
Psychosocial problems & 73 & 10.86 \\
Spinal disorders & 51 & 7.58 \\
Stroke & 34 & 5.05 \\
\hline
\end{tabular}

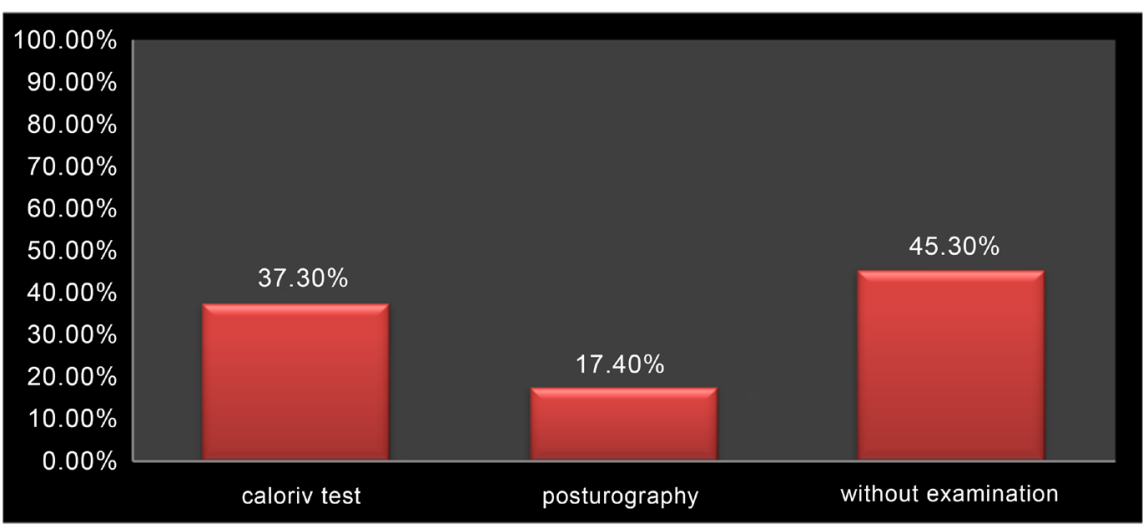

Figure 3. Distribution of subjects according to the presence of the test and posturography caloric test.

the indication of repositioning maneuvers and Vestibular Rehabilitation, even without the need for otoneurological additional tests [5].

About medical diagnosis (Table 4), much of the population studied $65.47 \%$ $(\mathrm{N}=440)$ had some source of disease in the peripheral vestibular system as the cause of dizziness which corroborates the findings of Ganança et al. [5] and Ganança et al. [19] who estimated that the origin of dizziness is correlated with a peripheral system disorder in about $85 \%$ of cases.

\section{Conclusion}

The prevalence of gender in vestibular rehabilitation clinic was female. The average 
Table 4. Distribution of subjects according to the topodiagnosis.

\begin{tabular}{ccc}
\hline HD & N & $\%$ \\
\hline Dizziness of peripheral origin & 440 & 65.47 \\
Dizziness of central origin & 30 & 4.46 \\
Dizziness clarify & 202 & 30.05 \\
\hline
\end{tabular}

age of the population served was 54.9 years old. Dizziness of the rotary type was the most prevalent. Tinnitus was the most commonly reported symptom otoneurological. Nausea, pallor, sweating, tachycardia and vomiting have been associated with dizziness for $63.68 \%$ of the population. The most commonly reported complaint time was $0-5$ years. The normal bilateral hearing was the predominant auditory pattern. The disorder of the peripheral vestibular system was the most prevalent. The Hypertension was the most commonly reported comorbidity.

\section{Conflicts of Interest}

The authors declare no conflicts of interest regarding the publication of this paper.

\section{References}

[1] Norré, M.E. (1990) Rationale of Rehabilitation Treatment of Peripheral Vestibular Disorders. Acta AWHO, 3, 121-123.

[2] Caovilla, H.H., Ganança, M.M., Munhoz, M.S.L., Silva, M.L.G. and Frazza, M.M. (1997) Body Balance and Its Disorders: Part II: Dealing with the Giddy Patient. Brazilian Journal of Otorhinolaryngology, 2, 47-51.

[3] Moreira, D.A., Bohlsen, Y.A., Momensohn-Santos, T.M. and Cherubini, A.A. (2006) Study of the Handicap in Patients with Dizziness Complaint, Associatedornot with the Tinnitus Symptom. Arquivos Internacionais de Otorrinolaringologia, 10, 270-277.

[4] Ganança, C.F., Ganança, M.M., Caovilla, H.H., Munhoz, M.S.L. and Ganança, F.F. (1999) Vertigo Notebook: The Vertigo Explained: Diagnostic Guidelines. Brazilian Journal of Otorhinolaryngology, 56, 2-20.

[5] Ganança, F.F., Castro, A.S.O., Branco, F.C. and Natour, J. (2004) Impact of Dizziness on the Quality of Life in Patients with Peripheral Vestibular Dysfunction. Brazilian Journal of Otorhinolaryngology, 70, 94-101. https://doi.org/10.1590/S0034-72992004000100016

[6] Ganança, F.F. (1998) Adult Vestibular Disorders: Major Clinical Frames. In: Ganança, M.M., Vieira, R.M. and Caovilla, H.H., Eds., Princípios de Otoneurologia, Editora Atheneu, São Paulo, 1-2.

[7] Zanardini, F.H., Zeigelboim, B.S., Jurkiewicz, A.L., Marques, J.M. and Bassetto, J.M. (2007) Vestibular Rehabilitation in Elderly with Dizziness. Pró-Fono Revista de Atualização Científica, 19, 177-184. https://doi.org/10.1590/S0104-56872007000200006

[8] Nishino, L.K., Ganança, C.F., Manso, A., Campos, C.A.H. and Korn, G.P. (2005) Personalized Vestibular Rehabilitation: Medical Chart Survey with Patients Seen at the Ambulatory of Otoneurology of I.S.C.M.S.P. Brazilian Journal of Otorhino- 
laryngology, 4, 440-447. https://doi.org/10.1016/S1808-8694(15)31196-4

[9] Traldi, L., Pedalini, M.E.B., Bittar, R.S.M. and Bottino, M.A. (2004) Relationship between Caloric Test Resultsand Evolution of Patients Undergoing Vestibular Rehabilitation. Arquivos Internacionais de Otorrinolaringologia, 8, 294-298.

[10] Charles, J., Fahridin, S. and Britt, H. (2008) Vertiginous Syndrome. Australian Family Physician, 37, 299.

[11] Neuhauser, H.K., Von Brevern, M., Radtke, A., Lezius, F., Feldmann, M., Ziese, T., et al. (2005) Epidemiology of Vestibular Vertigo: A Neurotologic Survey of the General Population. Neurology, 65, 898-904. https://doi.org/10.1212/01.wnl.0000175987.59991.3d

[12] Bittar, R.S., Oiticica, J., Bottino, A., Ganança, F.F. and Dimitrov, R. (2013) Population Epidemiological Study of the Prevalence of Dizziness in the City of São Paulo. Brazilian Journal of Otorhinolaryngology, 6, 688-698. https://doi.org/10.5935/1808-8694.20130127

[13] Bittar, R.S.M. (1997) Labyrinthine Hormones: Steroid Hormones, Estrogen and Progesterone. Arquivos Internacionais de Otorrinolaringologia, 1, 32.

[14] Cohen, H.S. (2002)Disability in Vestibular Dysfunctions. In: Herdman, S.J., Ed., Vestibular Rehabilitation, Manole, Barueri, 369-382.

[15] Ganança, M.M., Caovilla, H.H., Munhoz, M.S.L., Silva, M.L.G. and Ganança, F.F. (1997) Checkmate in the Dizziness. I-VPPB in Check. Acta Awho, 16, 129-137.

[16] Caovilla, H.H. (1998) The Body Balance and the Disorders of Human Communication. In: Ganança, M.M., Vieira, R.M. and Caovilla, H.H., Eds., Principles of Otoneurology, Editora Atheneu, São Paulo, 1-2.

[17] Honrubia, V. (2002) Quantitative Vestibular Function Tests and Clinical Examination. In: Herdman, S.J., Ed., Vestibular Rehabilitation, Manole, Barueri.

[18] Fetter, M. (2002) Vestibular System Dysfunction. In: Herdman, S.J., Ed., Vestibular Rehabilitation, Manole, Barueri, 91-102.

[19] Ganança, M.M., Caovilla, H.H., Munhoz, M.S.L., Silva, M.L.G., Ganança, F.F. and Ganança, C.F. (1999) The Many Faces of Positional Vertigo. Atualgeriatra, 4, 8-14. 